\title{
Effects of Water Intake on Biochemical Parameters and Performance During Resistance Exercise
}

\author{
Murat Kasap ${ }^{1}$, İbrahim Erdemir ${ }^{2}$, Recep Fatih Kayhan ${ }^{3}$ \\ ${ }^{1}$ Uludag University, Faculty of Sports Sciences, Bursa/Turkey \\ ${ }^{2}$ Balıkesir University, School of Physical Education and Sports, Balikesir/Turkey \\ ${ }^{3}$ Recep Tayyip Erdogan University, School of Physical Education and Sports, Rize/Turkey \\ Corresponding: İbrahim Erdemir, Balıkesir University, School of Physical Education and Sports, Balikesir, Turkey.
}

Received: October 14, 2018

doi:10.11114/jets.v6i12.3689
Accepted: November 1, $2018 \quad$ Online Published: November 9, 2018

URL: https://doi.org/10.11114/jets.v6i12.3689

\begin{abstract}
The study aims to determine whether water intake during resistance training impacts the amounts of potassium $(\mathrm{K}+)$, sodium $(\mathrm{Na}+)$, magnesium $(\mathrm{Mg})$, and calcium $(\mathrm{Ca})$ and to identify the effects of the reactions of these minerals on performance. Ten male university students aged between 20 and 23 participated in the study. The participants did five different previously-determined resistance exercises ( 3 sets of $8 \mathrm{RM}$ ). During the training program, the participants did the resistance exercises by not consuming water in the first week and consuming water in the second week. (Pre-exercise and exercise days routine food and fluid intake was maintained, fluid intake restriction was applied only during exercise) The participants' weight, body mass index (BMI), percent body fat, systolic and diastolic pressure, lactate, Borg scale ratings, and $\mathrm{K}+\mathrm{Na}+\mathrm{Mg}$, and $\mathrm{Ca}$ were determined before and after the exercises. Training volume was recorded. Performing the exercises without water intake produced a significant increase in $\mathrm{K}+$. During the exercises done with water intake, there was a significant increase in $\mathrm{Na}+$. No statistical differences were determined in the volume of exercise done with and without water intake. The study shows that water intake during high-intensity resistance training does not have any effect on the volume of exercise. In addition, the changes in $\mathrm{Na}+$ and $\mathrm{K}+$ parameters do not affect the volume of exercise. Although loss of minerals is statistically significant in exercise without water, it is understood that the total amount of minerals lost is not enough to induce a physiological change or a performance change in the total resistance training volume. Water, regardless of the volume and intensity of exercise, promotes balance of metabolism and prevents performance degradation that can occur during sport events (Murray et al., 1991). For this reason, water should be consumed not only in sports activities but also in daily activities.
\end{abstract}

Keywords: mineral, thirst, hydration, dehydration, strength training

\section{Introduction}

Water is an indispensable component of metabolism. Homeostasis for sustainability of body fluid levels is important. Water intake is versatile. Since water intake can cause significant body fluid volume change, intake should be done with caution to prevent such major changes (Armstrong et al., 2016). Professional sports medical associations suggest that to prevent performance reduction, total body weight (BW) loss should not exceed 2 percent (Sawka et al., 2007). Water intake goal during exercise can prevent excessive water loss. Significant fluid-electrolyte balance changes might result in decreased athletic performance. The amount to compensate for water loss depends on individual sweating during exercise, exercise duration, exercise intensity, and water intake. Sport players should periodically consume water (when applicable) if they are expected not to experience excessive dehydration. While doing long exercises, especially those lasting more than 3 hours, water should be replaced (Casa et al., 2000; Sawka et al., 2000). As the perspiration speed and sweat electrolyte concentration of sport players differ according to metabolic requirements, genetics, temperature, training status, exercise duration, clothes, equipment, and weather conditions, recommending a water and electrolyte intake frequency is challenging. Dehydration with perspiration depends on various factors such as temperature, humidity, and type of physical activity (O'neal et al., 2013). Intense physical activity might radically increase metabolic rate. Therefore, during long physical activities where perspiration is increased due to high temperature, the correct amount and quality of water intake should be followed to avoid negative effects on exercise performance (Armstrong et al., 2012). There is a great deal in the literature regarding the amount of water needed in our body and the effect of 
dehydration on metabolism (Hew et al., 2003; Martinez et al., 2018; Noakes et al., 1985; Noakes et al., 2005; Sawka et al., 2007). Water loss by perspiration during high-level physical activities and performance decreases are determined by changes in body mass index (BMI) measurement, blood-biochemical parameters $(\mathrm{Na}+\mathrm{K}+, \mathrm{Mg}$, and $\mathrm{Ca}$ ), and intracellular fluid amount (Aslankeser, 2010; Noakes, 2002; Sawka et al., 2007). During vigorous exercise of $>20$ minutes in duration, water loss exceeds electrolyte loss, especially in hot conditions (Squire, 1990). Hypohydration arises from the loss of at least $2 \%$ of body water without adequate replacement. Losses of $>2 \%$ produce incremental deficits in physical performance; losses of $>5 \%$ cause substantially decreased ability to continue with physical activity and put an individual at risk for life-threatening dehydration, heat stroke, and heat exhaustion (Naghii, 2000).

Therefore, water intake is often disregarded during physical activity. Unfortunately, studies concerning the effects of water intake or the opposite scenario during high-intensity physical activity on blood serum, sodium (Na+), potassium $(\mathrm{K}+)$, magnesium $(\mathrm{Mg})$, and calcium $(\mathrm{Ca})$ elements, and performance are few.

Since the water fluid balance is maintained with water intake during resistance exercise, any type of performance decrease is unexpected. Since avoiding water intake during resistance exercise will disrupt body fluid balance, decreased performance is expected (Kırbas et al., 2015). Avoiding water intake during resistance exercise will change $\mathrm{Na}+, \mathrm{K}+\mathrm{Mg}$, and Ca parameters (Reece et al., 2014).

The main objective of our study was to determine effects of water intake or avoiding water intake in blood $\mathrm{Na}+\mathrm{K}+$, $\mathrm{Mg}$, and $\mathrm{Ca}$ parameters during high-intensity resistance exercise.

\section{Method}

The study aims to determine whether water intake during resistance training impacts the amounts of potassium $(\mathrm{K}+)$, sodium (Na+), magnesium $(\mathrm{Mg})$, and calcium $(\mathrm{Ca})$ and to identify the effects of the reactions of these minerals on performance. Ten male university students aged between 20 and 23 participated in the study. The participants did five different previously-determined resistance exercises ( 3 sets of 8RM).

\subsection{Subjects}

In this study, 10 healthy men, aged $20-23$ y (mean, $21.50 \pm 0.85 \mathrm{y}$, height: $177.10 \pm 2.77 \mathrm{~cm}$ ), from a physical education and sport department voluntarily participated. All participants signed an informed consent form prior to participation in the study according to the Declaration of Helsinki and were assessed with the Borg Scale after all the exercises. The study was approved by the University of Uludag Human Ethics Committee (10 April 2012 2012-8/5).

\subsection{Research Protocol}

1 Repetition Maximum (1RM) Testing: The mass of all weight plates and equipment was determined with a precision scale and was used to calculate the 1RM of each exercise. The 1RM tests (Simao et al., 2007) were assessed in the following order: bench press, shoulder press, leg extension, leg curl, and lat pull-down. All machine exercises were performed on ESJIM fitness equipment (ESJIM Isotonic Plate System equipment, 4, TR). To minimize possible errors in the 1RM tests, the following strategies were adopted: (a) all subjects received standard instructions on the general routine of data assessment and the exercise technique of each exercise before testing, (b) the exercise technique of subjects during all testing sessions was monitored and corrected as needed, and (c) all subjects received verbal encouragement during testing. During the 1RM testing, each subject performed a maximum of five 1RM attempts of each exercise with 5-minute rest between attempts. After the 1RM load in a specific exercise was determined, an interval of not shorter than 10 minutes was allowed before the 1RM determination of the next exercise. Standard exercise techniques were followed for each exercise. No pause was allowed between the eccentric and concentric phases of repetition or between repetitions. This means speed of movement was 2:0:3, totally $5 \mathrm{sec}$. For a repetition to be successful, a complete range of motion as is normally defined for the exercise had to be completed. Participants warmed up prior to testing by cycling for 5 minutes on a stationary bicycle. After a 1-minute rest period, participants were familiarized with each of the resistance machines by performing $8-10$ repetitions of a light load ( $\sim 50 \%$ of predicted $1 \mathrm{RM})$. After a 1 minute of rest, participants performed a load ( 80\% of estimated 1RM) through the full range of motion. After each successful performance, the weight increased until a failed attempt occurred. One-minute rests were given between each attempt and the 1-RM was attained within 5 attempts and 5 minutes rest separated each test (Seo et al., 2012).

Water Amount: The amount of water given to participants during exercise $(70 \mathrm{~min})$ was calculated as $5 \mathrm{ml}$ per body weight (body weight $72.05 \pm 6.26 \mathrm{~kg}$ ) and $(361.00 \pm 30.89 \mathrm{ml}) 14-160 \mathrm{C}$ (Costa et al., 2013; Noakes et al., 1985).

Blood (Na, K, Mg, and Ca) Analysis: Blood samples taken by a specialist nurse before the warm-up and end of the exercise. Blood analysis was made in the Analytical Chemistry Laboratory at Balikesir University, Faculty of Arts and Science. The blood of the participants was placed in $10 \mathrm{ml}$ chemistry tubes where $5 \mathrm{ml}$ corresponded to serum phase separation and was placed in 5ml TCA solution. Phase separation of blood was done, and pure water was added to achieve 10ml. Obtained solutions were analyzed (Perkin Elmer Analyst 800 Atomic Absorption Spectrometer, Waltham, 
MA, USA) for $\mathrm{Na}, \mathrm{K}, \mathrm{Mg}$, and Ca elements.

Exercise: The exercise program was applied with 3 sets of 8RM, 5-minute break between exercise, and 3-minute break between sets. Exercise volume has been calculated like that;

Exercise volume (for one exercise $)=(8 \mathrm{RM})$ lifted weight $\mathrm{x}$ Repetition $\mathrm{x}$ Sets

RM: 100kg, 8RM: 75kg, Repetition: 8, Sets:3

Exercise volume (for one exercise) $=80 \times 8 \times 3=1920 \mathrm{~kg}$

Total exercise volume $=$ Bench press volume + Shoulder press volume + Leg extension volume + Leg curl volume + Lat pull-down volume.

\subsection{Research Design}

The research was carried out over 3 weeks. Participants avoided their own training or any other exercise or activities for at least 48 hours before the experiment. Participants did a regular warm-up routine before starting each exercise program. Determination of maximal power was carried out in the first week. In the second week, before the exercise program, body weight and body fat ratio, BMI (Tanita Body Composition Analyzer, BC-418 Tokyo Japan), and blood pressure (Braun BP 2550, Germany) were determined, and the level of lactate was determined (Lactate Scout, Leipzig-Germany) with lactate measurement strips for each participant. The Borg Scale was applied for each participant before the exercises (with and without water intake). After a 10-min. warming up, selected exercises (bench press, shoulder press, leg extension leg curl, lat pull-down) for the main section were performed by the participants without water intake during exercise. After the exercise was completed by the participants, before cooling down, measurements made before the exercise were repeated. In the third week, the tests and the same resistance exercise program applied in the second week were repeated by the participants with water intake. Resistance exercise was applied between 11:0012:10 (total 70min.). The exercises were carried out in a fitness center at $210 \mathrm{C}$ temperature, and with 52 percent humidity. Temperature and humidity measurements were made with UNI-T UT333, Hong Kong.

\subsection{Statistical Analysis}

Data were analyzed by using the IBM SPSS Statistics version 20 software for Windows (IBM Corp., 2011, Armonk, NY, USA). Descriptive statistics were presented as mean and standard deviation. A Shapiro-Wilk test was performed to test for normality and paired-samples $t$ tests were applied to determine the variables between pre-test and post-test. The statistical significance level was set at $\mathrm{p}<0.05$ and $\mathrm{p}<0.01$.

\section{Results}

There were statistical differences $(\mathrm{p}=0.091)$ between the volume of training performed (total weight) of participants for exercise without water intake $(14240.90 \pm 1981.92 \mathrm{~kg})$ and exercise with water intake $(14683.70 \pm 1819.87 \mathrm{~kg})$.

Table I. Mean values $( \pm \mathrm{SD})$ of physiological parameters of participants

\begin{tabular}{lcccccc}
\hline \multicolumn{1}{c}{ Variable } & \multicolumn{2}{c}{ Exercise (Without Water) } & \multicolumn{3}{c}{ Exercise (With Water) } \\
& Pre-Test & Post-Test & $\mathbf{p}$ & Pre-Test & Post-Test & P \\
\hline Body Mass (kg) & $72.05 \pm 6.26$ & $71.39 \pm 6.19$ & $<\mathbf{0 . 0 0 * *}$ & $71.56 \pm 6.51$ & $71.54 \pm 6.62$ & 0.87 \\
BMI $\left(\mathbf{k g} / \mathbf{m}^{2}\right)$ & $23.01 \pm 1.97$ & $22.77 \pm 1.96$ & $<\mathbf{0 . 0 0 * *}$ & $22.81 \pm 2.06$ & $22.81 \pm 2.06$ & 1.00 \\
Systolic BP $(\mathbf{m m H g})$ & $121.00 \pm 11.01$ & $123.00 \pm 12.52$ & 0.51 & $124.00 \pm 6.99$ & $117.00 \pm 8.23$ & $<\mathbf{0 . 0 4 *}$ \\
Diastolic BP $(\mathbf{m m H g})$ & $73.50 \pm 9.44$ & $67.00 \pm 13.38$ & 0.08 & $69.00 \pm 9.94$ & $74.00 \pm 8.43$ & 0.18 \\
Lactate (mmol) & $1.59 \pm 0.29$ & $4.340 \pm 2.32$ & $<\mathbf{0 . 0 0 * *}$ & $1.75 \pm 0.28$ & $4.79 \pm 2.13$ & $<\mathbf{0 . 0 0 * *}$ \\
Borg RPE Scale & $13.40 \pm 1.17$ & $14.10 \pm 1.52$ & $<\mathbf{0 . 0 3}^{*}$ & $12.70 \pm 0.95$ & $13.40 \pm 0.97$ & $<\mathbf{0 . 0 0 * *}$
\end{tabular}

${ }^{*} \mathrm{p}<0.05, * * \mathrm{p}<0.01$, BMI: Body Mass Index, Borg RPE Scale: Rating of Perceived Exertion Scale, BP: Blood pressure

Table II. Pre- and post-test values of $\mathrm{K}, \mathrm{Na}, \mathrm{Ca}$, and Mg parameters with and without water intake

\begin{tabular}{|c|c|c|c|c|c|c|}
\hline \multirow[b]{2}{*}{ Variable } & \multicolumn{3}{|c|}{ Exercise (Without Water) } & \multicolumn{3}{|c|}{ Exercise (With Water) } \\
\hline & Pre-Test & Post-Test & p & Pre-Test & Post-Test & $\mathbf{p}$ \\
\hline $\bar{K}(\mathrm{mg} / \mathrm{L})$ & $863.60 \pm 356.47$ & $1499.98 \pm 515.47$ & $<0.00 * *$ & $386.54 \pm 136.16$ & $483.22 \pm 265.23$ & 0.19 \\
\hline $\mathrm{Na}(\mathrm{mg} / \mathrm{L})$ & $505.89 \pm 181.08$ & $365.37 \pm 168.02$ & 0.16 & $345.61 \pm 154.88$ & $541.55 \pm 281.72$ & $<0.02 *$ \\
\hline $\mathrm{Ca}(\mathrm{mg} / \mathrm{L})$ & $111.90 \pm 29.24$ & $118.34 \pm 27.64$ & 0.56 & $109.28 \pm 71.58$ & $102.60 \pm 34.68$ & 0.82 \\
\hline $\mathrm{Mg}(\mathrm{mg} / \mathrm{L})$ & $15.05 \pm 5.76$ & $10.84 \pm 7.98$ & 0.25 & $8.30 \pm 4.84$ & $13.60 \pm 6.96$ & 0.06 \\
\hline
\end{tabular}

$* \mathrm{p}<0.05, * * \mathrm{p}<0.01$ 
As Table II shows, the pre- and post-test values of $\mathrm{K}+$ for exercise without water intake indicated an increase at $\mathrm{p}=0.004$ level. Pre- and post-test values of $\mathrm{Na}+$ for exercise with water intake showed a $\mathrm{p}=0.019$ increase.

\section{Discussion}

Various studies in the literature have indicated that water intake during long exercises has effects on performance of sport players (Costa et al., 2013; Noakes, 2002; Singh \& Peters, 2014). On the other hand, for sport players with high resistance capacity, it was determined that in short high-intensity exercises, $\mathrm{Na}+\mathrm{K}+$ ATPase pump activity increased, and tiredness was delayed (Aughey et al., 2007). However, during high-intensity exercises (especially during resistance exercises), since perspiration and fluid loss are low, there are few studies in the literature that investigated the effects of dehydration or certain minerals at water intake $(\mathrm{Na}+\mathrm{K}+, \mathrm{Mg}$, and $\mathrm{Ca}$ ) on performance (Casa et al., 2000; Coyle, 2004; Gonzalez-Alonso et al., 1995).

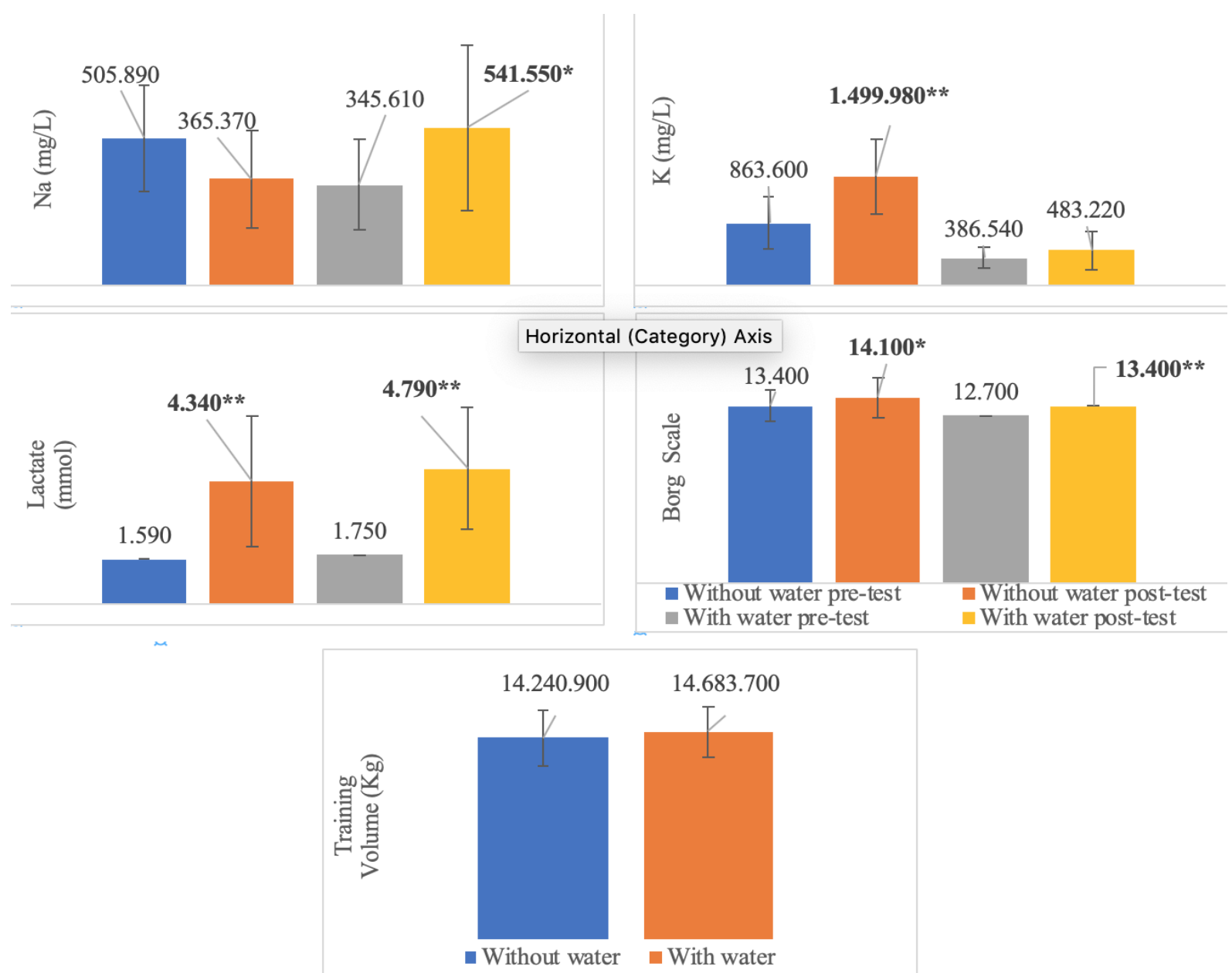

Figure 1. Comparison of the pre- and post-test of Na, K, Blood Lactate, Borg Scale and Exercise Volume

Sodium plays an important role in preserving intercellular fluid, muscle contractions-relaxations, and nervous system (Costa et al., 2013). In this study, decreased $\mathrm{Na}+$ values between pre- and post-test during exercise without water intake increased for pre- and post-test during exercise with water intake. Singh and Peters (2014) found in the running and cycling field and laboratory research that water intake preserved blood Na osmolarity between 275 and 295 mmol.kg-1. Similar results in our study confirmed that water intake during exercise had effects on blood Na+ values (Aslankeser, 2010; Hamouti et al., 2010; Ocal, 2007).

During exercise, fluid loss in the body occurs with energy consumption and perspiration. It is known that excessive loss results in decreased performance (Noakes, 2002). During exercise without water intake, a significant decrease was found regarding body weight and BMI pre- and post-test difference. During exercise with water intake, no significant decrease was identified between body weight and BMI pre- and post-test difference. The literature supports the fact that BMI decreases due to water intake limitations (Aslankeser, 2010; Costa et al., 2013; Noakes, 2002; Pecanha et al., 2014; Singh \& Peters, 2014).

In this study, no significant difference between performance values during exercise with or without water intake was 
identified. Pre- and post-test differences between measurement parameters during exercise with or without water intake created significant differences among blood $\mathrm{Na}+\mathrm{K}+$, and BMI values as a result of dehydration. Studies showing similarities in the findings are seen in the literature. Previous studies (Ftaiti et al., 2001; Gonzalez et al., 1999; Greiwe et al., 1998; Houston et al., 1981; Jacobs, 1980; Nielsen et al., 1981; Sjogaard \& Saltin, 1982; Webster et al., 1988; Webster et al., 1990) reported the effects of dehydration on muscular strength and power, the results are inconclusive. To our knowledge, anaerobic exercise performance has been previously evaluated in 4 studies, 2 of which employed Wingate-type cycle ergometer tests (Webster et al., 1990; Yoshida et al., 2002) and 2 of which employed supramaximal endurance tests (Sawka et al., 2007; Vincent et al., 2015). Dehydration (8\% body mass loss) did not affect performance in a supramaximal ( 1 min.) treadmill run (Vincent et al., 2015).

On the other hand, a $21 \%$ reduction in anaerobic power and a $10 \%$ reduction in anaerobic capacity in dehydrated (5\% body mass loss) subjects have been demonstrated (Webster et al., 1988).

Both of these studies used similar methodologies so that their disparate results are not easily explained.

Moreover, Yoshida et al., (2002) stated in their study that during dehydration due to exercise, aerobic exercise tends to be affected more than anaerobic exercise. In studies of top- and bottom-extremity anaerobic resistance without water intake, performance decreased due to dehydration when exercises lasted more than 15 seconds (Jones et al., 2008). Studies in the literature indicated that dehydration decreases performance in aerobic exercise (Costa et al., 2013; Ocal, 2007; Singh \& Peters, 2014).

As a result, from Jones, et all. (Jones et al., 2008) investigation suggest that active dehydration of $3.1 \%$ via exercise in a hot, humid environment has a negative effect on anaerobic muscular power. The results of our investigation although loss of minerals is statistically significant in exercise without water, it is understood that the total amount of minerals lost is not enough to induce a physiological change or a performance change in the total resistance training volume.

In our research, since no high-level sport player with a suitable training program was found, and due to the high cost of measurement parameters (blood tests), the number of participants was limited to 10 male subjects studying at the University.

In this study, no significant difference between performance values during exercise with or without water intake was found. However, although exercise was low, effects of dehydration were significant on serum $\mathrm{Na}+, \mathrm{K}+$, body weight, and BMI values. Body weight and BMI decreased in resistance exercise without water intake, caused by a body fluid decrease. Because of the sport education levels, numbers, physiological fluid requirements, differences in perspiration rates, as well as sample size, the short test durations might have caused lower levels in the results. Similar studies might be applied to high-level sport players to help the time effect of water intake during short intense exercises in long training to be understood more clearly. In terms of physiology, since aerobic performance is based on aerobic capacity, a high aerobic capacity of participants (large capacity activities of cellular fluid compartment) is an important criterion to determine the effect of water intake or dehydration on performance during anaerobic exercise. Therefore, as aerobic capacities of participants are undermined, the clear effect of dehydration on performance during resistance training is determined.

Water affects athletic performance more than any other nutrient. Consuming fluids in sufficient amounts is essential for normal cellular function and of particular importance to athletes in thermal regulation. Water is the largest component of the body, representing from $45-70 \%$ of a person's body weight. Muscle tissue is approximately $75 \%$ water, whereas fat tissue is about 20\% water (Baechle \& Earle, 2000). Regardless of exercise duration and intensity, water intake equal to the expected dehydration will help in keeping metabolism balanced and will prevent performance decreases. Either during exercise or during daily activity, dehydration occurs even without perspiration, so that individuals should drink water even if not thirsty.

\section{References}

Armstrong, L. E., Casa, D. J., Emmanuel, H., Ganio, M. S., Klau, J. F., Lee, E. C., \& Wingo, J. E. (2012). Nutritional, physiological and perceptual responses during a summer ultraendurance cycling event. J Strength Cond Res., 26, 307-318. https://doi.org/10.1519/JSC.0b013e318240f677

Armstrong, L. E., Johnson, E. C., McKenzie, A. L., Ellis, L. A., \& Williamson, K. H. (2016). Endurance cyclist fluid intake, hydration status, thirst, and thermal sensations, gender differences. Int J Sport Nutr Exerc Metab 26(2), 161-167. https://doi.org/10.1123/ijsnem.2015-0188

Aslankeser, Z. (2010). The effects of anaerobic training on central-peripheral fatigue and recovery periods. Doctoral thesis, Cukurova Universitesi Saglık Bilimleri Enstitusu, Adana.

Aughey, R., Murphy, K., Clark, S., Garnham, A., Snow, R., \& Smith, D, et al. (2007). Muscle Na+-K+ ATPase activity 
and isoform adaptations to intense interval exercise and training in well-trained athletes. $J$ Appl Physiol 103(1), 39-47. https://doi.org/10.1152/japplphysiol.00236.2006

Baechle, T. R., \& Earle, R. (2000). Essentials of Strength Training and Conditioning (2nd ed.). Champaign, IL, Human Kinetics. p. 246.

Boone, C, Hoffman, J, Gonzalez, A, Jajtner, A, Townsend, J, \& Baker, K, et al. (2016). Changes in plasma aldosterone and electrolytes following high-volume and high-intensity resistance exercise protocols in trained men. $J$ Strength Cond Res 30(7), 1917-1923. https://doi.org/10.1519/JSC.000000000001276

Brooks, G., Fahey, T., \& Baldwin, K. (2005). Obesity, body composition, and exercise. Exercise physiology-human bioenergetics and its application, 4th edition., New York: McGraw Hill. pp. 617-648.

Casa, D. J., Armstrong, L. E., Hillman, S. K., Montain, S. J., Reiff, R. V., Rich, B. S., \& Stone, J. A. (2000). National athletic trainers association position statement fluid replacement for athletes. J Athl Training 35(2), 212-224.

Costa, R. J., Teixeira, A., Rama, L., Swancot, A. J., Hardy, L., \& Lee, B., et al. (2013). Water and sodium intake habits and status of ultra-endurance runners during a multi-stage. Nutr. J., 12(1), 13. https://doi.org/10.1186/1475-2891-12-13

Coyle, E. F. (2004). Fluid and fuel intake during exercise. Journal of Sports Sciences, 22(1), 39-55. https://doi.org/10.1080/0264041031000140545

Ftaiti, F., Grelot, L., Coudreuse, J. M., \& Nicol, C. (2001). Combined effect of heat stress, dehydration and exercise on neuromuscular function in humans. Eur J Appl Physiol 84, 84-87. https://doi.org/10.1007/s004210000339

Gonzalez, A. J., Calbet, J. A. L., \& Nielsen, B. (1999). Metabolic and thermodynamic responses to dehydration induced reductions in muscle blood flow in exercising humans. J. Physiol., 520, 577-589. https://doi.org/10.1111/j.1469-7793.1999.00577.x

Gonzalez-Alonso, J., Mora-Rodriguez, R., Below, P. R., \& Coyle, E. F. (1995). Dehydration reduces cardiac output and increases systemic and cutaneous vascular resistance during exercise. Journal of Applied Physiology, 79(5), 1487-1496. https://doi.org/10.1152/jappl.1995.79.5.1487

Greiwe, J S., Staffey, K. S., Melrose, D. R., Narve, M. D., \& Knowlton, R. G. (1998). Effects of dehydration on isometric muscular strength and endurance. Med. Sci. Sports Sci., 30, 284-288. https://doi.org/10.1097/00005768-199802000-00017

Hamouti, N., Coso, J., Estevez, E., \& Mora-Rodriguez, R. (2010). Dehydration and sodium deficit during indoor practice in elite European male team players. Eur. J. Appl. Physiol., 10(5), 329-336. https://doi.org/10.1080/17461391003632022

Hew, T., Chorley, J., Cianca, J., \& Divine, J. (2003). The incidence risk factors and clinical manifestations of hyponatremia in marathon runners. Clin. J. Sport Med., 13(1), 41-47. https://doi.org/10.1097/00042752-200301000-00008

Houston, M. E., Marrin, D. A., Green, H. J., \& Thomson, J. A. (1981). The effect of rapid weight loss on physiological functions in wrestlers. Phys. Sportsmed, 9, 73-78. https://doi.org/10.1080/00913847.1981.11711208

Jacobs, I. (1980). The effects of thermal dehydration on performance of the Wingate Anaerobic Test. Int. J. Sports Med., 1, 21-24. https://doi.org/10.1055/s-2008-1034625

Jones, L., Cleary, M., Lopez, R., Zuri, R., \& Lopez, R. (2008). Active dehydration impairs upper and lower body anaerobic muscular power. J. Strength Cond Res., 22(2), 455-463. https://doi.org/10.1519/JSC.0b013e3181635ba5

Kırbas, S., Tetik, S., Aaykora, E., \& Duran, B. (2015). An examination of the impact of regular exercise participation on blood platelet parameters. World Journal of Medical Sciences, 12(2), 79-82.

Martinez, S, Aguilo, A, Rodas, L, Lozano, L, Moreno, C, \& Tauler, P. (2018). Energy, macronutrient and water intake during a mountain ultramarathon event, The influence of distance. J. Sports Sci., 36(3), 333-339. https://doi.org/10.1080/02640414.2017.1306092

Murray, R., Eddy, D., Paul, G., Seifert, J., \& Halaby, G. (1991). Physiological responses to glycerol ingestion during exercise. American Physiological Social., 1,144-149. https://doi.org/10.1152/jappl.1991.71.1.144

Naghii, M. R. (2000). The significance of water in sport and weight control. Nutr. Health., 14, 127-132. https://doi.org/10.1177/026010600001400205

Nielsen, B., Kubica, R., Bonnesen, A., Rassmussen, I. B., Stokolosa, J., \& Wilk, B. (1981). Physical work capacity after dehydration and hyperthermia: a comparison of the effect of exercise versus passive heating and sauna and diuretic 
dehydration. Scand J. Sport Sci., 3, 2-10.

Noakes, T. (2002). Hyponatremia in distance runners: fluid and sodium balance during exercise. Curr. Sports Med. Rep., 1(4), 197-207. https://doi.org/10.1249/00149619-200208000-00003

Noakes, T., Goodwin, N., Rayner, B., Branken, T., \& Taylor, R. (1985). Water intoxication a possible complication during endurance exercise. Med. Sci. Sports Exerc., 17(3), 370-375.

Noakes, T., Sharwood, K., Speedy, D., Hew, T., Reid, S., \& Dugas, J., et al. (2005). Three independent biological mechanisms cause exercise-associated hyponatremia: Evidence from 2,135 weighed competitive athletic performances. PNAS 102(51), 18550-18555. https://doi.org/10.1073/pnas.0509096102

Ocal, D. (2007). Searching some blood parametres for indication of dehydration following training in swimmers. Master's thesis, Gazi Universitesi Saglik Bilimleri Enstitusu, Ankara.

O'neal, E. K., Caufield, C. R., Lowe, J. B., Stevenson, M. C., Davis, B. A., \& Thigpen, L. K. (2013). 24-h Fluid kinetics and perception of sweat losses following a 1-h run in a temperate environment. Nutrients, 6(1), 37-49. https://doi.org/10.3390/nu6010037

Pecanha, T., Paula-Ribeiro, M., Campana-Rezende, E., Bartels, R., Marins, J., \& Lima, J. (2014). Water intake accelerates parasympathetic reactivation after high-intensity exercise. Int. J. Sport Nutr. Exerc. Metab., 24(5), 489-496. https://doi.org/10.1123/ijsnem.2013-0122

Reece, J., Urry, L., Cain, M., Wasserman, S., Minorsky, P., \& Jackson, R. (2014). Campbell biology, Boston: Pearson. 138-142.

Sawka, M. N., Burke, L. M., Eichner, E. R., Maughan, R. J., Montain, S. J., \& Stanchelfed, N. S. (2007). American college of sports medicine position stand. Exercise and fluid replacement. Med. Sci. Sports Exerc., 39(2), 377-390.

Seo, D. I., Kim, E., Fahs, C. A., Rossow, L., Young, K., Ferguson, S. L., \& Lee, M. K. (2012). Reliability of the one-repetition maximum test based on muscle group and gender. Journal of Sports Science \& Medicine, 11(2), 221.

Simao, R., Farinatti, P., Polito, M., Viveiros, L., \& Fleck, S. (2007). Influence of exercise order on the number of repetitions performed and perceived exertion during resistance exercise in women. J. Strength Cond Res., 21(1), 23. https://doi.org/10.1519/00124278-200702000-00005

Singh, N., \&Peters, E. (2014). Artificial neural networks in the determination of the fluid intake needs of endurance athletes. AASRI Procedia, 8, 9-14. https://doi.org/10.1016/j.aasri.2014.08.003

Sjogaard, G., \& Saltin, B. (1982). Extra and intracellular water spaces in muscles of man at rest and with dynamic exercise. Am. J. Physiol, 243, R271-R280. https://doi.org/10.1152/ajpregu.1982.243.3.R271

Squire, D. L. (1990). Heat illness. Fluid and electrolyte issues for pediatric and adolescent athletes. Ped. Clin. N. Amer., 37, 1085-1109. https://doi.org/10.1016/S0031-3955(16)36976-0

Vincent, G., Lamon, S., Gant, N., Vincent, P., MacDonald, J., Markworth, J., \& Hickey, A. (2015). Changes in mitochondrial function and mitochondria associated protein expression in response to 2-weeks of high intensity interval training. Front Physiol., 6, 15. https://doi.org/10.3389/fphys.2015.00051

Webster, S. F., Rutt, R. A., \& Weltman, A. (1988). Effects of typical dehydration practices on performance. Med. Sci. Sports Exerc., 20, 20.

Webster, S. F., Rutt, R., \& Weltman, A. (1990). Physiological effects of weight loss regimen practiced by college wrestlers. Med Sci Sports Exerc., 22, 229-234.

Yoshida, T., Takanishi, T., Nakai, S., Yorimoto, A., \& Morimoto, T. (2002). The critical level of water deficit causing a decrease in human exercise performance. Eur. J. Appl. Physiol., 87(6), 529-534.

https://doi.org/10.1007/s00421-002-0651-z

\section{Copyrights}

Copyright for this article is retained by the author(s), with first publication rights granted to the journal.

This is an open-access article distributed under the terms and conditions of the Creative Commons Attribution license which permits unrestricted use, distribution, and reproduction in any medium, provided the original work is properly cited. 